\title{
Using Co-polymers to Improve Soil Strength and Mitigate Fugitive Dust Emissions: Laboratory Evaluation
}

\author{
Chun-Hsing $\mathrm{Ho}^{1, *}$, Ziyan $\mathrm{Wu}^{1}$, Zhonghan Zhang ${ }^{1}$, Pengxiang $\mathrm{Zhao}^{2}$, and Junxin Huang ${ }^{3}$ \\ ${ }^{1}$ Department of Civil Engineering, Construction Management, and Environmental Engineering, Northern Arizona University, PO Box \\ 15600, Flagstaff, Arizona, USA \\ ${ }^{2}$ College of Safety Science and Engineering, Xi' an University of Science and Technology, Xi'an, Shaanxi 710054, China \\ ${ }^{3}$ School of Resource Environment and Safety engineering, Hunan University of Science and Technology, Xiangtan 411201, China
}

\begin{abstract}
A report by the Federal Highway Administration (FHWA) in the USA stated that there are over 1.4 million miles (2.3 million kilometres) of unpaved roads in the United States, over 1/3 of the U.S highway systems. Unpaved roads play an important role in transporting goods and passengers in between urban and suburban areas. However, most unpaved roads are gravel and unimproved that have exposed a severe issue for local transportation networks. Particularly when unpaved roads are in wet conditions (rain or snow), the muddy and soft surface roads have created a hazardous environment for traffic operations. The paper presents an improvement plan using co-polymer dust suppressants to be mixed with soils collected in Northern Arizona. Soil samples were mixed with the co-polymer dust suppressants using four concentration rates $(0 \%$ water, $1 \%, 3 \%$, and $5 \%$ by weight). A series of tests were performed including surface strength (resistant penetration) test, dynamic rolling test, and unconfined compressive shear test. The results show that the addition of co-polymer dust suppressants in the soil has improved the soil shear strength and decreased dust emissions, provided the results from the surface strength test, dynamic rolling test, and unconfined compressive strength test are promising.
\end{abstract}

\section{Introduction}

Fugitive dust, a type of atmospheric matter, is potentially generated from unpaved roads by natural winds or vehicle movements [1]. Based on the Environmental Protection Agency (EPA)'s monitoring data across the United States, approximately $65 \%$ of atmospheric matters are originally from unpaved roads, meaning that unpaved road is the major source that produces fugitive dust emissions [2, 3]. Bai et al.'s research illustrates that fugitive dust is harmful to human health, especially respiratory system, and in some situation, fugitive dust can even cause premature death for sensitive people $[4,5]$. In addition to the concern on the human health and environmental pollution, the lower strength of the unpaved road is one of the factors that significantly influences the safety of traffic operations in transporting goods and passengers, resulting in economic loss due to poor road conditions $[6,7]$. Until 2014, nearly $50 \%$ of roads in the United States were unpaved [8], which indicates that half of the roads in the US generates nearly $65 \%$ of the fugitive dust emissions. Thus, it is important for highway agencies to maintain unpaved roads in a well condition to provide a safe and healthy environment for vehicle drivers.

According to the definition from International Organization for Standardization (ISO), fugitive dusts are defined as dusts with diameter are less than 75 micrometers, specially, particular matters (PM) whose diameters are not greater 10 micrometers (PM 10) and not greater 2.5 micrometers (PM 2.5) [9]. Therefore, particles passing through the \#200 sieve can be indicated as fugitive dust emissions and may have significant impacts on human health and surrounding environment [10].

Commonly used dust control measures include vehicle transportation control, water spreading, and dust control suppressants. Chemical dust suppressants are widely used in construction sites or local roads to control the fugitive dust generations. Some research indicates that chemical products are able to improve the physicochemical and mechanical features of soils so as to increase the soil strength of unpaved road [11]. This paper aims to evaluate the effectiveness of polymer dust suppressants in the improvement of performance (shear strength, surface strength, and dust mitigation) of the soil specimens.

In this paper, co-polymer dust suppressants (CDS) were obtained from a local company in Phoenix, USA. Soils tested in this paper are sampled from two locations: Sedona and Flagstaff, Arizona. The co-polymer dust suppressants are diluted into four different concentrations $(0 \%, 1 \%, 3 \%$, and $5 \%)$ to be mixed with both soils to prepare soil specimens. The soil samples passing through the \#200 sieve were used to mix with the CDS and then

\footnotetext{
* Corresponding author: chun-hsing.ho@nau.edu
} 
were undertaken the three tests, including the surface strength (resistance penetration) test, the dynamic rolling test, and the unconfined compressive strength test.

\section{Sample Preparation}

\subsection{Sieve analysis and soil classification of two soil samples}

As previously mentioned, two types of soil were collected at two different locations in Northern Arizona: Sedona and Flagstaff. The sieve analysis was performed on each type of soils and the particle size distribution curves were created (Figure 1). For soils collected in Sedona, 90.92\% of the material passed the \# 4 (4.75 $\mathrm{mm})$ sieve and $1.19 \%$ was finer than sieve \# $200(0.075 \mathrm{~mm})$. The uniformity coefficient and the coefficient of curvature of the soil were calculated to be 5.91 and 0.44 . Thus, the soil from Sedona is classified as poorly sand (SP). Using the same method, the soil sampled from Flagstaff is classified as poorly sand with silty clay (SP-SC).

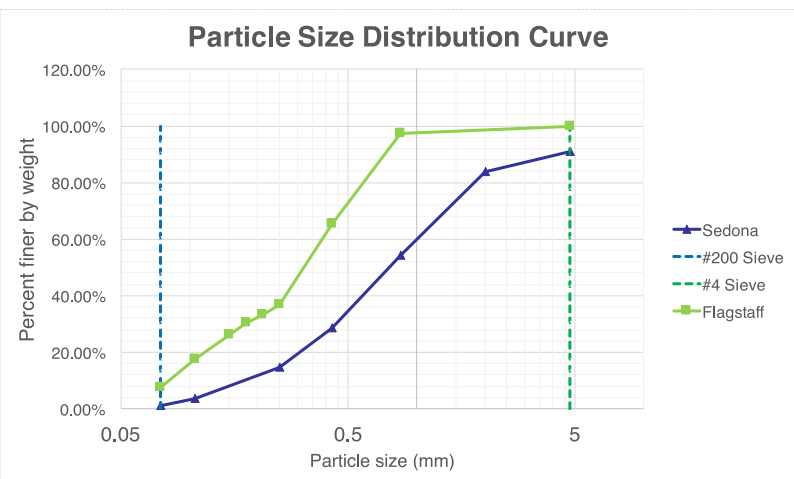

Fig. 1. Particle size distribution curves of two types of soils

\subsection{Specimens preparation}

Four different concentrations of the co-polymer dust suppressants were prepared, namely, $0 \%, 1 \%, 3 \%$, and $5 \%$ by weight. The $0 \%$ concentration is pure water mixed with the soil, referring to the control group. The moisture content of specimens was kept at $15 \%$. The specimens were prepared by spraying the suppressant solutions on the soil surface at a rate of $1.59 \mathrm{~L} / \mathrm{m}^{2}$ until the specimens were fully mixed with the co-polymer dust suppressants.

\section{Test Results and Discussions}

\subsection{Surface penetration test}

After the four specimens were well mixed with the copolymer dust suppressants, a portable penetrometer was used to test the surface strength (penetration resistance) to allow us to understand the effectiveness of CDS in the improvement of surface penetration resistance. The hand penetrometer was used to punch through the two types of soil specimen with four concentration rates (Figure 2). After the penetration, a resistant reading was immediately received. A total of 10 tests were performed and the average surface strength and its standard deviation (STD) were calculated. All results were shown in Table 1.

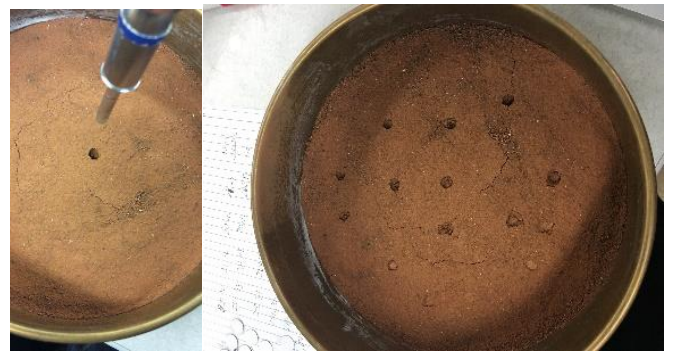

Fig. 2. Surface strength test before and after the treatment (3\% copolymer mixed with Sedona soil)

Table 1. Surface strength test results

\begin{tabular}{|c|c|c|c|c|}
\hline $\begin{array}{c}\text { Soil } \\
\text { Classification }\end{array}$ & \multicolumn{2}{|c|}{ SP-SC } & \multicolumn{2}{c|}{ SP } \\
\hline $\begin{array}{c}\text { Concentration } \\
(\%)\end{array}$ & $\begin{array}{c}\text { Ave. } \\
(\mathrm{KPa})\end{array}$ & $\begin{array}{c}\text { STD } \\
(\mathrm{Kpa})\end{array}$ & $\begin{array}{c}\text { Ave. } \\
(\mathrm{KPa})\end{array}$ & $\begin{array}{c}\text { STD } \\
(\mathrm{Kpa})\end{array}$ \\
\hline 0 & 469 & 192 & 772 & 236 \\
\hline 1 & 6,771 & 408 & 1,951 & 301 \\
\hline 3 & 15,079 & 947 & 3,775 & 606 \\
\hline $5(*)$ & 17,926 & N/A & 17,926 & N/A \\
\hline
\end{tabular}

Note: $(*)$ : the reading exceeds the maximum capacity of the portable penetrometer.

As can be seen in Table 1, the surface strength of both SPSC and SP soils increased substantially after the copolymer dust suppressants were added. In addition, the CDS appeared to work better in the SP-SC soil than the SP soil, indicating the silty clay was a better source than sand to be bounded with the CDS.

\subsection{Dynamic rolling test}

As vehicles travel on unpaved roads, significant amount of fugitive dust emissions are generated, thus compromising the traffic safety and human health. It is of interest to evaluate if the CDS would effectively decrease the amount of dust emissions. Since there is no test standards available to help understand the above phenomena, we used a mechanical shaker with modifications to produce a rolling like test, named "dynamic rolling test". This test was used to assess the resistance capacity of the CDS treated specimens under the action of rolling effect. A total of 12 rubber bunch balls $(3.3 \mathrm{~cm}$ in diameter, each) were placed on the surface of a CDS treated specimen covered by a $3-\mathrm{kg}$ weight mass (18 $\mathrm{cm}$ in diameter), and the entire set was then located on a mechanical shaker, running/shaking for 6 minutes. During shaking, rubber bunch balls were able to roll over the surface of the CDS treated specimen with a means to simulate dynamic vehicle travelling on road surface. After a dynamic test was completed, the CDS treated specimen was undertaken a sieve analysis again with an intent to determine how many fine aggregate (passing a \#200 sieve) were generated. In comparison with the original data in Figure 1, we were able to evaluate the effectiveness of the CDS in mitigating fugitive dust 
emissions. The SP-SC and the SP soils with four concentration rates were tested for dynamic rolling and the results of particle distribution were displayed in Figure 3 and Table 2.

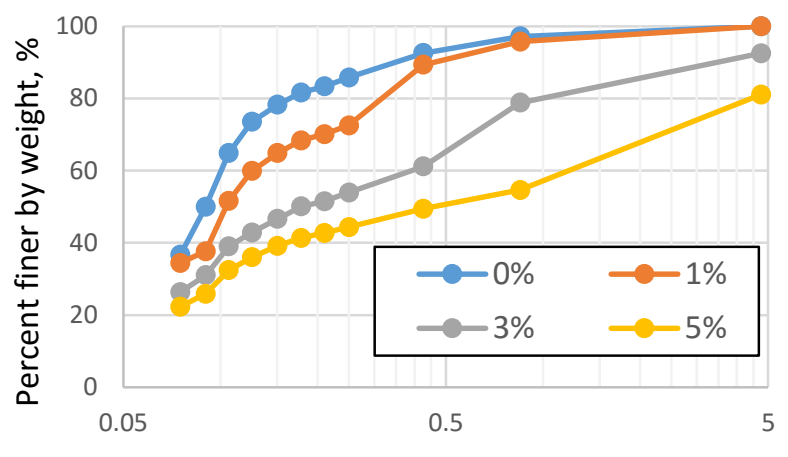

Particle size, $\mathrm{mm}$

a)

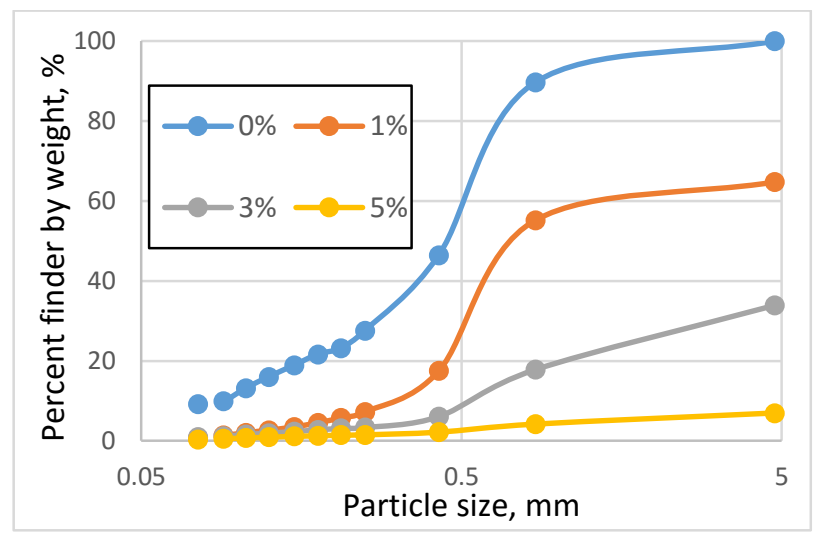

b)

Fig. 3. particle distribution of the a) SP soil, and b) SP-SC soil

Table 2. \% passing \#200 sieve after dynamic rolling test

\begin{tabular}{|l|r|r|r|r|}
\hline & \multicolumn{4}{|c|}{ Concentration rate } \\
\hline Soil & $0 \%$ & $1 \%$ & $3 \%$ & $5 \%$ \\
\hline SP-SC & 9.2 & 0.8 & 0.9 & 0.3 \\
\hline SP & 36.7 & 34.4 & 26.3 & 22.3 \\
\hline
\end{tabular}

Unit: in \%

It is noticeable in both Figure 3 and Table 2 that the CDS significantly holds finer particles from being worn away from the rolling actions, provided the percent of fine particles passing \#200 dropped as the concentration rate increased. Particularly, the CDS works well with the SP$\mathrm{SC}$ soil than the SP soil in bonding the silty soil particles, resulting in the decrease of generation of dust emissions (finer particles passing \#200).

\subsection{Shear strength test}

The shear strength of unpaved roads plays an important role in controlling its serviceability. Ratnaweera and Meegoda [12] performed a series of unconfined compression tests on chemically contaminated finegrained soils to review the reduction of shear strength and shear strain behaviors. The Unconfined Compression
Strength (UCS) test is perhaps one of the most common and simplest tests that can be carried out within a short period of time in a laboratory. This test includes the application of an axial vertical load through loading platens, using strain-control conditions, to a cylindrical sample of laterally unconfined CDS treated specimen (Figure 4). The unconfined compressive strength (UCS) is defined as the maximum unit stress obtained from monotonic load testing. The SP-SC and the SP soils mixed with four concentration rates of CDS were undertaken the UCS tests according to the ASTM D2166 standard. In order to obtain a wider range of shear strength of CDS treated specimens, the concentration rates were modified and increased as: $0 \%$ (control group), $5 \%, 10 \%$, and $15 \%$ by weight. The new CDS mixed specimens (SP-SC and the SP soils) were produced in the laboratory. The CDS mixed specimens were compacted and placed in split molds dimensioned of $100 \mathrm{~mm}$ in diameter and $200 \mathrm{~mm}$ in height. After compaction, all UCS specimens were removed from molds and placed on a UCS apparatus for testing (Figure 4). The UCS results are exhibited in Figure 5 .

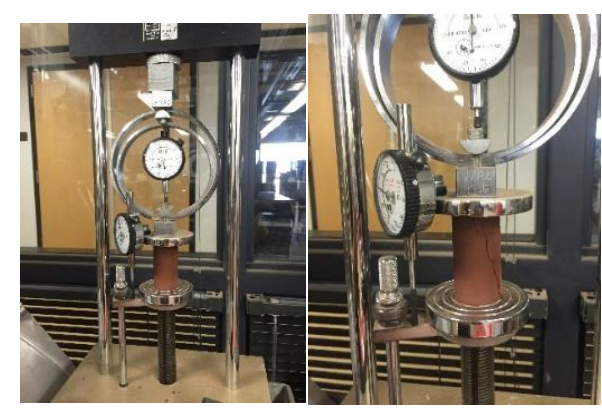

Fig. 4. Unconfined compressive strength test (before and after testing)

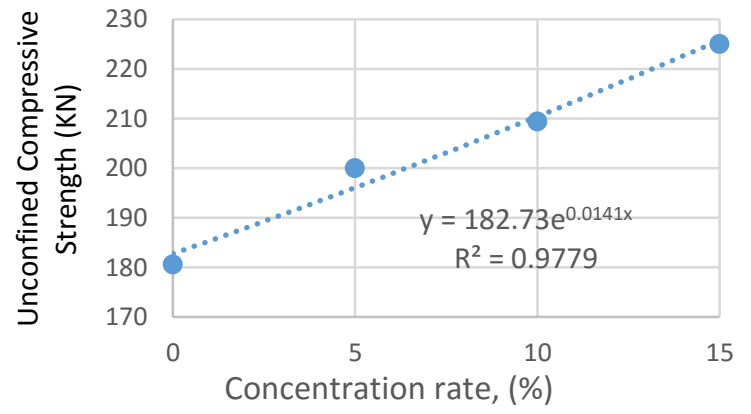

a)

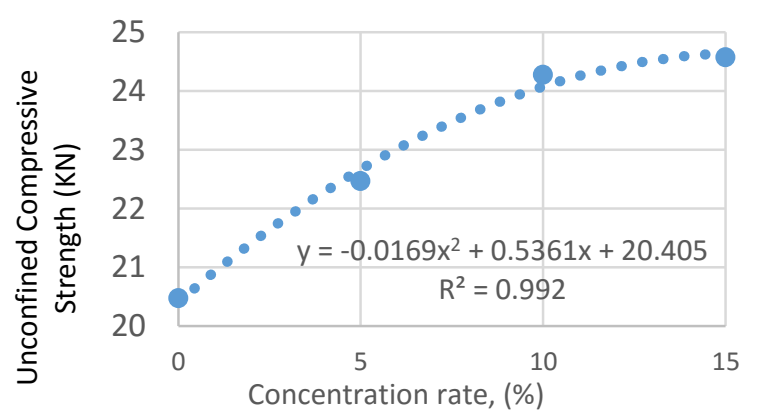

b)

Fig. 5. Unconfined compressive shear test for a) SP-SC soil, and b) SP soil 
The UCS results also indicated that the effectiveness of CDS in the improvements of shear strength on the two soils (SP-SC and SP) is substantial. Specifically, the SP$\mathrm{SC}$ mixed with the CDS has the greater UCS results than the SP's. This is also confirmed with the other two surface strength and the dynamic rolling tests. It is also observed that the unconfined compressive strength tends to be stable after a $10 \%$ concentration rate. This indicates that the optimum concentration rate of co-polymer is between $10 \%$ to $15 \%$. In addition, the result suggests that other materials such as lime, fly ash, cement, etc. could be considered as additives to improve the shear strength of unpaved soil.

\section{Conclusions}

(1) The effectiveness of co-polymer dust suppressants in the improvements of performance of two soils (SP-SC and the SP) is substantial, provided the results from the surface strength test, the dynamic rolling test, and the unconfined compressive strength test were promising.

(2) The co-polymer dust suppressants seemed to have had better properties with the silty clay than the sand, given the SP-SC soil has greater surface strength and unconfined compressive strength, as well as better properties in mitigating fugitive dust emissions.

(3) The optimum concentration rate of co-polymer is between $10 \%$ to $15 \%$. In addition, the result suggests that other materials such as lime, fly ash, cement, etc. could be considered as additives to improve the shear strength of unpaved soil.

(4) For future research, it is recommended to mix copolymer dust suppressants with clayey soils (CL or ML) and compare their mechanical behaviors (shear strength and surface strength) with the silty clay (SC).

\section{References}

1. J. A. Gillies, J. G. Watson, C. F. Rogers, J. of the Air \& Waste Management Assoc., 49, 3-16, (2011)

2. T. G. Sanders, J. A. Quayenortey, D. Jorgensen, J. of Transportation Eng., 141, 1943-5436, (2015)

3. Environmental Protection Agency. (2006). National summary of particulate matter emissions in 2002, Triangle Park, NC (Oct. 12, 2011).

4. Z. Xi, Z. Feng, A. Li. "Synergistic coal dust control using aqueous solutions of thermoplastic powder and anionic surfactant." ElsevierB.V. (2017)

5. X. B. Bai, J. Liu, I. T. Yan, J. of Shaanxi University of Technology, (2005) (In Chinese)

6. T. G. Sanders, J. Q. Addo, A. Ariniello et al., J. Transp. Eng. 123, 393-397, (1997)

7. E. A. Subaida, S. Chandrakaran, N. Sankar, Geotextiles and Geomembranes, 27, 204-210, (2009)

8. Midwest Research Institute. Background Document for Revisions to Fine Fraction Ratios Used for AP-42 Fugitive Dust Emission Factors, (2006)
9. C. D. Cooper, F. C. Alley, F. C, Air Pollution Control-A Design Approach, the 4th Edition. Waveland Press, Incorporated, (2011)

10. X. Wang, W. J. Wang. "Urban dust pollution and its research of control method in China. Environmental Science \& Technology”, 37, 588-592 (2004) (In Chinese)

11. P. Ratnaweera, J. N. Meegoda, Geot. Testing J., 29, (2014)

12. P. Ratnaweera, J. N. Meegoda. Geot. Testing J., 29, 2, 1-8, (2006) 